\title{
Utilização Do Conceito Matriz Swat na Elaboração do Instrumento de Passagem de Plantão Médico
}

Autores: Márcio José Cardoso Amaral, Mauro Roberto Melchiori Bucco, Mauro Henrique De Sa Adami Milman

\section{Introdução}

A passagem de plantão, ato de transferir informações e responsabilidade entre os médicos, é reconhecida pela organização mundial da saúde como um dos elementos chave para qualidade e segurança. Erros médicos e eventos adversos são associados à má qualidade de comunicação durante as passagens de plantão e existem diversas ferramentas e intervenções para melhoria da comunicação e redução dos erros médicos. As unidades de urgência e emergência são áreas estratégicas, nas quais os pacientes estão mais vulneráveis a quebras na comunicação. Com o objetivo de explorar as oportunidades e amenizar as ameaças, favorecendo assim o alcance da missão, visão e objetivos institucionais, fundamentamos a utilização das fortalezas e na correção das fraquezas (matriz SWAT) na criação de um instrumento que permitisse focar no auxílio a memória, padronização de passagem de plantão, protocolos de passagem de plantão e que permitisse visualizar a movimentação intra-hospitalar do paciente.

\section{Métodos}

Estudo descritivo observacional que teve como referencial teórico o planejamento estratégico, o qual permitiu a construção do instrumento de passagem de plantão. Esse planejamento tem por finalidade adotar medidas decisivas, bem como resultados para condução de atitudes pró-ativas na gestão organizacional. Este estudo foi desenvolvida num hospital geral de nível secundário com 150 leitos de internação e 10 leitos de uti com atendimento no setor de urgência e emergência no modelo porta aberta em que a sistematização de passagem de plantão médico ainda não estava implantada. No estudo foram incluídos as unidades de internação de retaguarda do pronto socorro e a unidade de atendimento de urgência e emergência na especialidade clinica cirúrgica. Na fase de elaboração foram realizadas reuniões com a equipe médica para definição das fortalezas e fraquezas definindo assim as oportunidades e ameaças da matriz SWAT. Na segunda fase com a matriz SWAT desenhada foram propostas possíveis estratégias de intervenção advindas da análise e cruzamento dos fatores analisados criando assim o instrumento para o processo de passagem de plantão médico, desenvolvido e locado na pasta de evolução médica do prontuário individual, na plataforma TAZY de prontuário eletrônico, de forma a permitir visibilizar a movimentação do paciente nos diversos setores do hospital e na alta hospitalar. Na fase final de análise de dados foi desenvolvido um relatório gerencial institucional que permite visibilizar todos as passagens de plantão médico com as seguintes informações: nome e data nascimento, localização atual do paciente, diagnóstico clinico, informações relevantes e pendencias ou recomendações.

\section{Resultados}

A análise de acordo com o método de planejamento estratégico permitiv a identificação de fatores internos (fortalezas) relativos à passagem de plantão: clareza nas informações, tempo máximo de 5 a 10 minutos para a passagem de plantão, objetividade nas informações, ambiente tranquilo, agilidade na troca de informações, cooperação da equipe e compromisso da equipe. No que se refere às oportunidades como fator externo foi possível identificar: o bom relacionamento com outros profissionais da saúde e novos modelos de gestão implantados na instituição pela administração. Quanto aos fatores externos negativos (ameaças): a administração hospitalar, interrupções médicas e de outros profissionais durante a passagem de plantão.

Em relação a utilização do instrumento observamos 100\% de utilização para realização de passagem de plantão médico e 15\% de ausência de documentos nos prontuários. 10\% dos pacientes possuíam preenchimento incompleto do instrumento.
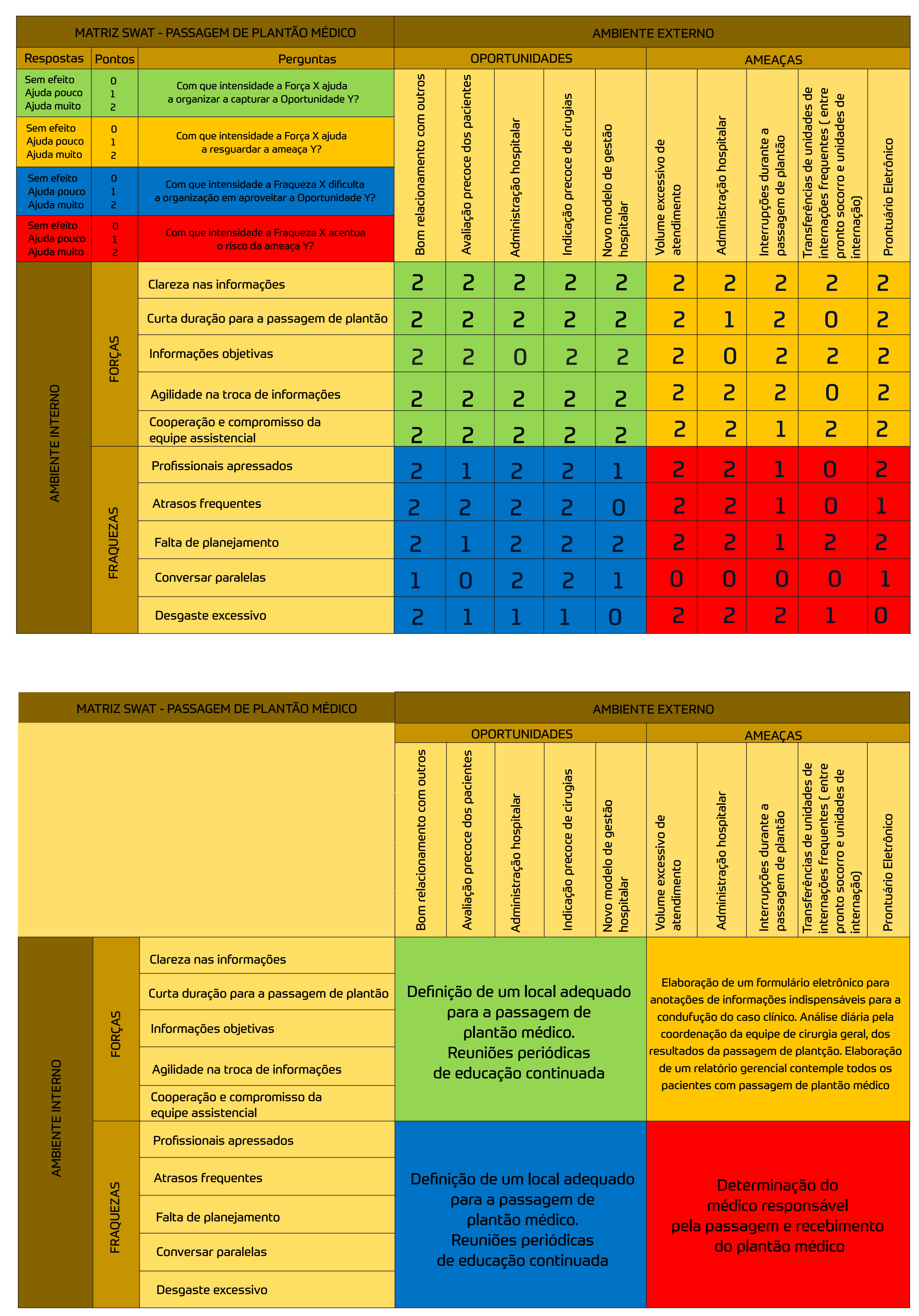

\section{Discussão}

A análise dos dados trouxe reflexões importantes para a compreensão da gestão do processo de passagem de plantão médico, identificando desafios e pontos críticos. Diante disso, quando analisados os fatores internos e externos, encontramos estratégias de ação condizentes com os resultados da construção da matriz fofa, que favoreceram o processo de passagem de plantão. A transmissão das informações durante a passagem de plantão deve ser objetiva, ao mesmo tempo concisa, garantindo assim o entendimento e o bom fluxo das informações. O presente estudo permitiu apontar contribuições importantes para um gerenciamento eficiente da passagem de plantão, procedimento que muitas vezes não cumpre o seu devido papel, acarretando prejuízos para os clientes e para a instituição

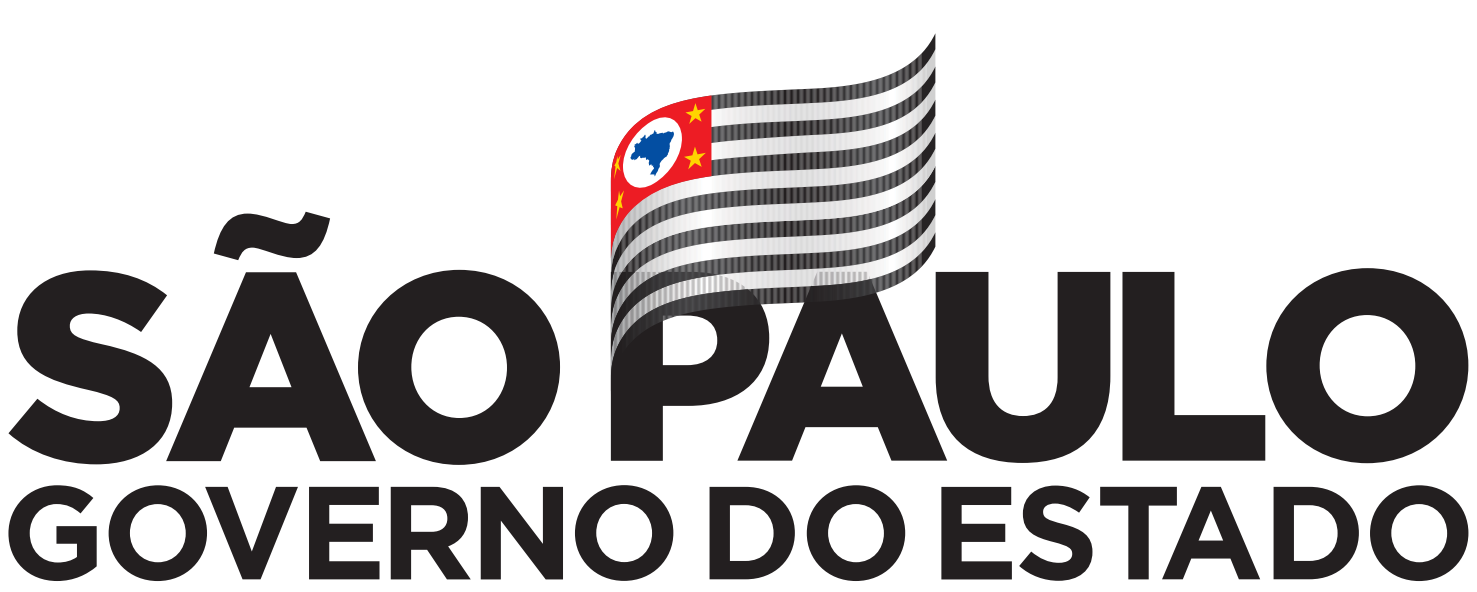

